\title{
OBITUARY
}

\section{Henry M. Fales, February 12, 1927-October 28, 2010}

$\mathrm{H}$ enry (Hank) M. Fales died October 28, 2010 at age 83. He was a prominent scientist at the National Institutes of Health and a valued member of ASMS.

Hank arrived at the NIH in 1953 just "to kill a year at NIH while looking for a good job at Dupont," he often would say. He stayed to become Chief of the Laboratory of Chemistry of the National Heart Institute (now National Heart, Lung, and Blood Institute). He was born in New York City in 1927 and enlisted in the Navy Air Corp in 1944. After the war, he studied chemistry at Rutgers University, and earned a Ph.D. (with R. A. Barnes) in 1952. He arrived at NIH, like many of his generation, transformed by WWII.

When Hank came to NIH, natural product chemistry was of great interest because investigation of the alkaloids in traditional medicinal plants promised new potential drugs. The difficulty was that structure determination of unknowns required isolation of $\sim 5$ milligrams of material of high purity. Hank recalled "We had to rely on chemical reactions, re-crystallization, and combustion analysis because the only analytical tools that available then were IR and UV spectrophotometers. Bob Highet and I were having trouble with the alkaloid amaryllisine whose formula was in doubt because it refused to give a reliable combustion analysis. We sent this to Klaus Biemann who gave it to Al Burlingame, then his student, who showed us the correct mass. We all published this as a message that MS could help in such cases. No big deal really, but it convinced us that we needed a MS of our own."

Hank selected an AEI MS902, a big investment at that time for his group (equivalent to $\sim \$ 700 \mathrm{k}$ in 2010 dollars) and then, recognizing the importance of gas chromatography, he purchased an LKB-9000 GC-MS. With colleagues Bill Milne and Bob Highet, he used this combination of high and low resolution instruments to tackle all types of structures from alkaloids to chemicals in poison ivy, insect pheromones, and Refsum's disease.

Hank was a catalyst. Following discussion of the newly developed chemical ionization method of Frank Fields and Burnaby Munson, he asked Marvin Vestal in 1968 to design a chemical ionization ion source for the MS-9, which Hank used to develop a series of paradigm-shifting papers on the application of chemical ionization to compounds of biomedical

Correspondence to: Sanford P. Markey; e-mail: markeys@mail.nih.gov

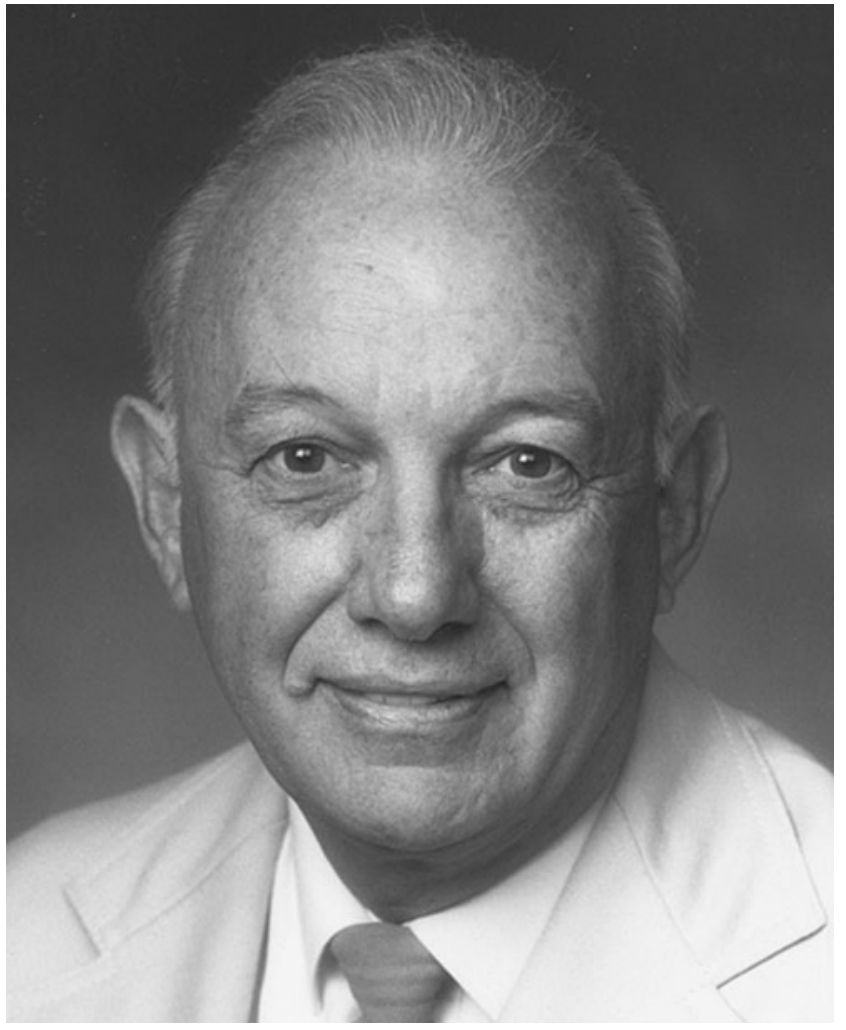

interest, demonstrating the immense value and interest in such alternatives to electron ionization. Similarly in the 1980s, he convinced Ron Macfarlane to build a Cf-252 plasma desorption time-of-flight instrument for his lab, leading to productive exploration of a wide variety of macromolecules.

Under Hank's direction, the Laboratory of Chemistry in NHLBI, became in the 1960s a world-renowned center for structural chemistry, integrating NMR, X-ray crystallography, and mass spectrometry. His group encouraged others with their experiments, particularly on alternative methods of ionization. In the 1970 s, using one of the first chemical ionization spectrometers, Hank took on the challenge of analysis of drugs in emergency room overdose cases with physician friend and neighbor Dr. Norman Law. He began a reference library of mass spectra that morphed subsequently into the current international resource, the NIST/EPA/NIH Mass Spectral Library. 
Hank's expertise in mass spectrometry and natural products led to his 3-month 1976 Amazon expedition on the NSF sponsored R/V Alpha Helix, led by Richard S. Schultes (Harvard) and Bo Holmstedt (Karolinska Institute). The plan was to do "a limited examination of many of the natural products down there before they were lost due to the encroachment of modern life. And we did do that although we rediscovered the wheel several times because literature was not available to us. Unfortunately, when the MS was installed, the ground point on the transformer was not installed correctly so that its frame was up to $220 \mathrm{~V}$. When I grounded the spectrometer with a piece of stout wire, the wire blew up and all of the power on the ship died. Then I found the mass spectrometer, which I had been admonished was the key to the whole voyage, would not scan. Consultations with LKB by Morse code were not much help (the radioman's 'tapping' finger, stung by a bee, was swollen) but we were successful and I remained in good graces with Schultes." Hank was more than competent in fields other than chemistry, so these Indiana Jones-like exploits did not surprise his friends or family.

Hank introduced many biomedical research scientists to mass spectrometry as a means of organic structure determination. He taught classes at the NIH night school (Foundation for Advanced Education in Sciences) for years and co-founded, with Fred Saalfeld (NRL), Henry Rosenstock (NBS, now NIST), and Joseph D'Amico (FDA), the Washington area mass spectrometry discussion group. His international reputation as an innovative scientist was recognized by his peers with multiple elected positions with the American Society for Mass Spectrometry: member-at-large (1976), Secretary (1978), Vice President for Programs (1990-1992), and President (19921994). He published over 350 papers and received the DHEW Superior Service Award in 1973 and 1986 and the Hillebrand Prize from the Chemical Society of Washington in 1977.

Hank was a very special person in his interactions with his many friends and colleagues at NIH and in the mass spectrometry community. He trained numerous post-docs and scientists, and was one of most easy-going, kind, genteel, and generous human beings that one could ever hope to meet. He tirelessly assisted many in re-orienting their careers and finding new opportunities at the NIH or in the greater scientific community. He was always willing to collaborate with anybody, a reflection of his scientific curiosity and unmatched ability to make a reliable direct physical measurement, always working on the instruments himself. He took an interest in almost anyone's scientific projects at the expense of his own work. It would be no exaggeration to claim he was one of the most collaborative and loved investigators on the NIH campus for the last 57 years.

Sanford P. Markey (with assistance from Bill Milne, Sonja Hess, Simone Koenig, Lewis Pannell, Jim Ferretti, Bob Balaban, and Michael Gottesman) National Institutes of Health Bethesda, MD, USA 